\title{
The Dialogical Potential of Facebook: The Case of Fashion Brands
}

\author{
https://doi.org/10.3991/ijim.v14i04.10892 \\ Marián Navarro-Beltrá $($ 凹) \\ Catholic University of Murcia (UCAM), Murcia, Spain \\ mnavarro2@ucam.edu \\ Irene Garcia Medina \\ Glasgow Caledonian University, Glasgow, Scotland \\ Pedro A. P. Correia \\ University of Madeira, Funchal, Portugal
}

\begin{abstract}
The main goal of this study is to examine the communication that fashion brands make through Facebook. It is intended to ascertain if the fashion brands use a communication strategy based on dialogue with their followers. In order to reach the objectives indicated above, a content analysis has been carried out (quantitative methodology) of 326 publications made through Facebook by H\&M, Zara and Ralph Lauren between January 1st and June 30th of 2017. The main results of this work show that, although Facebook has a wide dialogical potential, fashion brands do not use it to a great extent. Although we consider appropriate to have analyzed only the social network Facebook given its importance, this situation could be considered as the main limitation of the present study, since the fashion brands could, or not, be taking advantage of the dialogical potential of other social networks, such as Twitter or Instagram. It could be considered that this research stands out for studying a series of variables that allows organizations to know if they are using the dialogical potential offered by digital communication.
\end{abstract}

Keywords - Fashion, Facebook, social networks, social media, Internet, corporate communication, dialogue, stakeholders, content analysis

\section{Introduction}

The existing advertising saturation affects the effectiveness of campaigns [20]. For this reason, companies, instead of investing in a massive marketing, should focus on building relationships with customers and making personalized messages [12]. Regarding to this and because of the Internet, public relations and the way organizations involve their publics has changed considerably in recent years [21]. Thus, the emergence of new technologies has transformed the way in which companies interact and relate to their clients [31]. Therefore, smartphones acquire special relevance, because they are 
considered as a tool capable of producing new habits related to the use of the Internet [24].

In this context, organizations face the challenge of understanding the needs that their clients have before the digital communication channels [31], since and because of the information technologies, the public is more predisposed to understand the brand [8]. This situation requires that companies have a series of processes and knowledge that allow them to understand their clients and develop deeper connections with the purpose of forming emotional relationships with them [31].

The changes in the consumption patterns of the media involve organizations moving from distribution to information exchange [30]. In this way, companies should recognize that now one of its functions is to facilitate experiences of collaboration and dialogue with its publics [1], because this dialogue improves the brand experience of the consumers [30].

In this sense, we cannot forget that social media is based on dialogue, so organizations must pay attention to this situation with the purpose of participating on it and in dialoguing with its clients [12]. Therefore, it is common for large companies to use the means of social communication, such as Facebook [21].

Specifically, it is often considered that the fashion industry - which is behind the design, production, marketing and retail of clothing [13] - is closely linked to social media, a situation that can be explained by considering this industry as the most dynamic that exists, since from each few months new trends emerge and are shared with friends and family [29]. In fact, "fashion is a popular topic in social media" [4].

Thus, it can be considered that technological progress benefits the fashion sector, because it is able to attract customers to interact with brands [17]. Therefore, social networks in general and Facebook offer fashion brands a way to get in touch with their audiences, so that these channels of communication are considered by these companies as an opportunity to improve the relationship they have with their clients, and even as a tool to capture a wider audience [22].

It should be noted that Facebook is considered as a social network that allows bidirectional communication between companies and their public [6], in addition to be ideal to involve consumers with their reference brands [27]. In its turn, social networks can maintain the attention of its users for several hours [30] and they can access it through various devices, such as a computer or a smartphone [36]. In this way, and thanks to smartphones, users can be connected 24 hours a day [12]. Thus, it should be noted that, throughout the world, daily activity on Facebook is considerably high [26], since it is one of the most popular social networks that exist [36], [7].

At this point it is relevant to note that a popular research topic for public relations is the study of social media [21], although we cannot forget that the interest of the professionals of this discipline is relatively recent [35]. Because of the importance that the use of Facebook can imply for fashion brands such as communication tool with its stakeholders, it is essential to carry out research related to this topic of study.

The general objective of this study is based on examine the communications that fashion brands make through Facebook.

In a more concrete way, we want to know if fashion brands use a communication strategy based on dialogue with their followers. So, it's about finding out the degree of 
compliance between these companies with dialogues based on the provision of useful information for the public, the conservation of the visitors, the generation of repeated visits and the maintenance of the dialogical loop.

\section{Methodology}

In order to achieve the above-mentioned objectives, a quantitative methodology was used, so, it can be confirmed that this is an investigation is framed in the positivist paradigm. A content analysis of the publications made on Facebook by three prominent fashion brands was carried out. [3] defined content analysis as "a research technique for the objective, systematic, and quantitative description of the manifest content of communication." On the other hand, [18] considers that the "content analysis is a research technique for making replicable and valid inferences from texts (or other meaningful matter) to the contexts of their use. " In this regard, it should be noted that is a technique frequently used to analyze the content published by companies in social media (for example: [10];[23]; [21]; [28]; [30]; [33]; [34]. H\&M, Zara and Ralph Lauren were the fashion brands selected for carry out the present study, since they were the only three that appeared in the category "Apparel" of the ranking the best global brands (2016) made by Interbrand [14]. In case that the brand had more than one profile on Facebook the international was chosen one, and those that were specific to countries were discarded. All the profiles examined included the identification "verified account".

The accounts analyzed were:

- Zara: https://www.facebook.com/pg/Zara/posts/?ref=page internal

- H \& M: https://www.facebook.com/pg/hm/posts/?ref=page internal

- R. Lauren: https://www.facebook.com/pg/RalphLauren/posts/?ref=page internal

The period selected for the study was 6 months, since it was considered a sufficient period of time to observe the activity of a trademark in social networks. In particular, the publications made between January and June 30, 2017, as data collection took place in July of that year with the main goal of obtaining and analyzing the most recent information possible.

After selecting the dates and profiles specified above, a total of 326 publications were obtained: $60.4 \%$ belonged to Zara, $22.1 \%$ to H\&M and $17.5 \%$ to Ralph Lauren. All of these posts were coded and examined for this study. For this, a coding protocol was developed formed by diverse variables that collected information on the particularities of the publication, mentions, hashtags, images, videos, links, reactions, the times the publication were shared and the comments made by the brand and by its followers.

These variables, although adapted to carry out the present investigation, follow the dialogical principles established by [15] for Internet. Principles that have already proven to be adequate for communication carried out by the organizations through social networks, in particular of Twitter [2], [23],[28] and Facebook [11]; [37]. Thus, the principles dialogues examined in the present investigation were: 
- Providing useful information to the public: Stakeholders rely on institutions that provide useful information and organizations should be concerned about this issue and provide information that audiences consider to be of value [16]. In this sense it could be said that the priority public fashion on Facebook are customers and potential customers, so that images, videos, links and places to which they refer are an appropriate way of including useful information for these audiences.

- Conservation of visitors: Taking into account that the objective of the public relations is to create and strengthen links with its publics, organizations should not include links that are not related with the institution itself, as users may not return [16]. It is appropriate to examine both the use of these links, which we could call external, as corporate (those who redirect to other websites managed by the brand itself). In addition, making regular publications can also provide the conservation of visitors [28].

- Generation of repeated visits: One of the options that the organizations try to get audiences to visit them again is to include characteristics that make them attractive [16]. Therefore, the use of mentions and hashtags could be considered as important, since these tools can be perceived as relevant by its public.

- Maintenance of the dialogical loop: This principle is based on the need of organization to respond to questions, concerns and to the demands of audiences [16]. In this way, considers it appropriate to examine the comments made by the followers and by the brand itself for the purpose of observing the existence, or not, of conversations. In addition, the analysis of the reactions and the published is relevant, since these indicators also direct interaction on the part of the stakeholders with the publication.

For the study to be reliable, the limits of the categories included in the coding protocol, the coders were trained in a series of practical sessions and a previous trial with satisfactory results [40].

Finally, and for the purpose of examining the information collected, we used the SPSS software version 24. In particular we used the descriptive, the frequencies, the contingency tables, the multiple-response tables and line graphs. In addition, in order to verify the association between variables we used the Chi-square test of Pearson, in which we consider that the differences that are produced are statistically significant when $p<0.05$. In case this test showed a relationship between the variables, we observed the $\mathrm{V}$ of Cramer to know its intensity.

\section{$3 \quad$ Results - Providing Useful Information to Audiences}

Although the marks examined usually include photographs in their publications, they don't do it as often $\left(x^{2}=13.596, p=0.001\right)$, although the size of the effect found is small (V-Cramer $=0.204, p=0.001)$. In this way, Zara introduced images in $79.7 \%$ of the occasions, H\&M in $68.1 \%$ and Ralph Lauren in $56.1 \%$. There is also no agreement among brands when considering the number of photographs inserted in each post $\left(\mathrm{x}^{2}=\right.$ $170.575 ; \mathrm{p}=0.000)$, but in this case the size of the effect found is large $(\mathrm{V}-\mathrm{Cramer}=$ $0.511, \mathrm{p}=0.000$ ). Thus, and as can be observed in Table 1, H\&M includes an average 
of 4.03 images per publication, figure which is reduced when looking at other brands, since Ralph Lauren has an average of 2.3 and Zara of 0.97.

In this sense, it should be noted that differences statistically significant in terms of the brand when watching the inclusion of videos $\left(x^{2}=13.596, p=0.001\right)$, however, the size of the existing effect is small (V-Cramer $=0.204 ; p=0.001)$. On this occasion, and contrary to what happened in the case of the pictures, it is more frequent not to insert videos than to do it. In fact, Zara only introduces them in $20.3 \%$ of their posts, while H\&M incorporates them in $31.9 \%$ and Ralph Lauren in $43.9 \%$. In addition, it emphasizes that the three brands analyzed include at most one video per publication (see Table 1).

With reference to the links it should be noted that Zara resorts to them with great frequency, since it uses them in $92.4 \%$ of its posts, H\&M also $66.7 \%$ of the time, but Ralph Lauren only used in $26.3 \%$ of cases. These differences between brands are statistically significant $\left(\mathrm{x}^{2}=106.912 ; \mathrm{p}=0.000\right)$ and the size of the effect produces is large (V-Cramer $=0.573, p=0.000)$. In addition, it should be noted that Zara is the brand examined which includes more than one link, namely 2 , and only on one occasion $(0.5 \%)$ (see Table 1$)$, so that these dissimilarities between brands are also significant $\left(\mathrm{x}^{2}=107.218, \mathrm{p}=0.000\right)$, although this time the effect size is medium (V-Cramer $=$ $0.406, \mathrm{p}=0.000)$.

Table 1. Number of images, videos and links of the brands

\begin{tabular}{|l|l|c|c|c|c|c|}
\hline \multicolumn{2}{|c|}{ Brand } & N & Minimum & Maximum & Average & $\begin{array}{c}\text { Standard } \\
\text { deviation }\end{array}$ \\
\hline \multirow{3}{*}{ H\&M } & Number of images & 72 & 0 & 22 & 4.03 & 4.118 \\
\cline { 2 - 7 } & Number of videos & 72 & 0 & 1 & .32 & .470 \\
\cline { 2 - 7 } & Number of links & 72 & 0 & 1 & .67 & .475 \\
\hline \multirow{3}{*}{ Zara } & Number of images & 197 & 0 & 4 & .97 & .749 \\
\cline { 2 - 7 } & Number of videos & 197 & 0 & 1 & .20 & .403 \\
\cline { 2 - 7 } & Number of links & 197 & 0 & 2 & .93 & .277 \\
\hline \multirow{3}{*}{ Ralph Laurenyyyyyy} & Number of images & 57 & 0 & 26 & 2.30 & 4.528 \\
\cline { 2 - 8 } & Number of videos & 57 & 0 & 1 & 0.44 & .501 \\
\cline { 2 - 7 } & Number of links & 57 & 0 & 1 & 0.26 & .444 \\
\hline
\end{tabular}

Regarding to this, it is worth mentioning that $99.6 \%$ of the analyzed links redirect to a web page, so that there is only one $(0.4 \%$ of the occasions) that sends the user to another place, specifically Facebook. Zara is the brand that uses this link and does so in a publication in which there is only one link, so that the differences that are produce between companies when considering the place to which the first link leads are statistically significant $\left(\mathrm{x}^{2}=107.218, \mathrm{p}=0.000\right)$, with a medium effect size $(\mathrm{V}-\mathrm{Cramer}=$ $0.406, \mathrm{p}=0.000)$. 


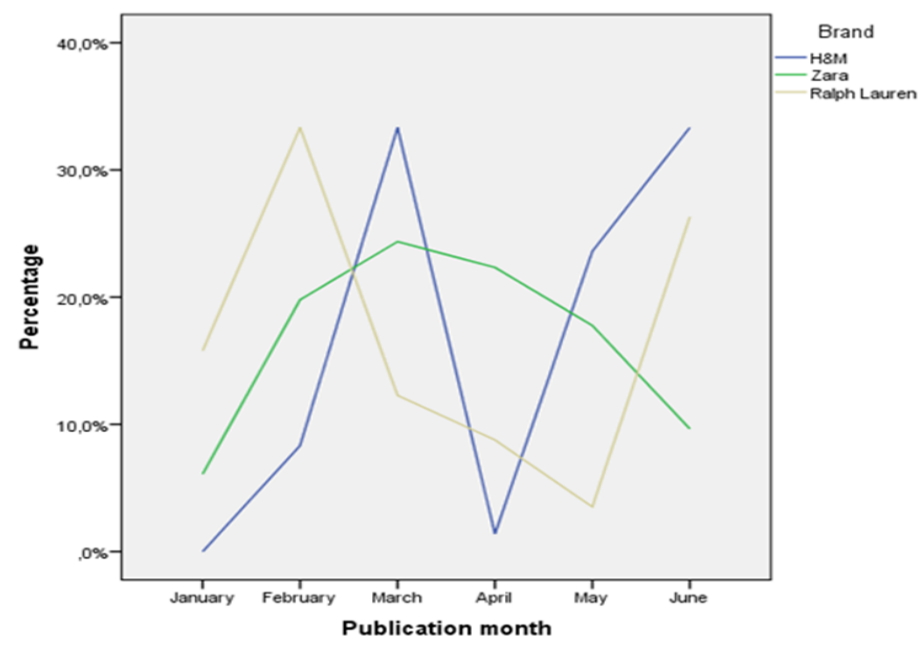

Fig. 1. Percentage of publication based on the month and the brand

However, statistically significant dissimilarities cannot be observed between brands when considering the day of the week in which the publication is made, since the three companies examined prefer to publish on Thursdays. Zara and Ralph Lauren agree that they do not usually write posts on Saturdays, although H\&M prefers not to do it on Tuesdays.

In addition, Ralph Lauren and Zara prefer to publish mid-month, specifically on day 16, but H\&M opted for day 2 (see figure 2). However, there are dates in which the brands do not insert any post, so that H\&M does not have no publication on days 7,14 , 29 and 31, Ralph Lauren chooses 4, 21 and 25 and Zara 4 and 15. Despite the dissimilarities observed between brands, the differences are not statistically significant.

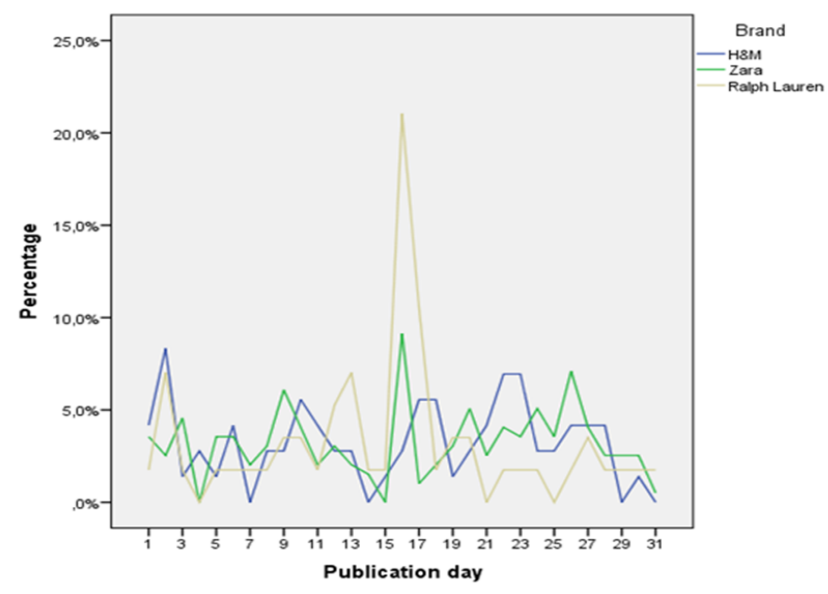

Fig. 2. Percentage of publication based on the day and the brand 
When considering the principle regarding the conservation of visitors, in addition of the regular publication, it is important to analyze the existence of corporate links that encourage users to browse websites managed by their own company. In this case, it can be said that there are no dissimilarities between brands examined, since all the links analyzed are corporate, so that none of the profiles examined has used an external link.

\section{Generation of Repeated Visits}

Although it is not often that brands insert mentions in their publications, the case of Zara is especially relevant, since it does not resort to them at any time.

On the other hand, Ralph Lauren introduces them in $14 \%$ of his post and $\mathrm{H} \& \mathrm{M}$ in $18.1 \%$. These differences are statistically significant $\left(\mathrm{x}^{2}=35.131, \mathrm{p}=0.000\right)$ and they have an average effect size $(\mathrm{V}-\mathrm{Cramer}=0.328, \mathrm{p}=0.000)$. Also, there is no consensus between the brands analyzed with reference to the number of mentions included $\left(\mathrm{x}^{2}=\right.$ $39.254, p=0.000)$, although the size of the effect found is small (V-Cramer $=0.245$; $\mathrm{p}=0.000$ ). In this way, the case of Ralph Lauren stands out, since it is the only company that inserts more than one mention in the same publication, specifically two, although it only does it on one occasion (1.8\% of the posts made by the brand) (see table 2 ).

In this sense, it emphasizes that the only brand that uses the same mention in more one occasion is H\&M. Specifically, it cites Style Scrapbook twice and Zara three times Larsson, TheWeeknd and The Weeknd.

With reference to hashtags, it should be noted that the differences that occur between marks are statistically significant $\left(\mathrm{x}^{2}=33.232, \mathrm{p}=0.000\right)$ and have a average effect size $(\mathrm{V}$-Cramer $=0.319, \mathrm{p}=0.000)$. So, and as you can see in Table 2, Zara is the only brand that prefers not to include hashtags in its publications, since it only inserts them in $42.1 \%$ of its posts, while Ralph Lauren does it in $66.7 \%$ and $\mathrm{H} \& \mathrm{M}$ in $79.2 \%$. In this way, Zara inserts an average of 0.76 hashtags per publication (with a minimum of 0 and a maximum of 3), a figure that rises to 0.93 in the case of Ralph Lauren (minimum $=0$, maximum $=2$ ) and to 1.17 in the case of $H \& M($ minimum $=0$, maximum $=4)$. These dissimilarities are significant $\left(x^{2}=73.769 ; p=0.000\right)$ and have an average effect size (V-Cramer $=0.336, \mathrm{p}=0.000)$.

\#HM is the hashtag that is repeated with greater assiduity in publications analyzed, since it appears in $39 \mathrm{H} \& \mathrm{M}$ post (54.17\% of the publications of said brand). The second most used hashtag is \# ss17, as it can be seen in six post of H\&M (8.33\%) and in 17 of Zara $(8.63 \%)$. On the other hand, Zara also quotes in 19 occasions to \#zaranewin (9.65\%) and Ralph Lauren turns 16 times to \#RLIconicStyle (28.07\%). 
Table 2. Number of mentions and hashtags per publication based on the mark

\begin{tabular}{|c|c|c|c|c|c|c|}
\hline & & & H\&M & Zara & $\begin{array}{c}\text { Ralph } \\
\text { Lauren }\end{array}$ & Total \\
\hline \multirow{16}{*}{ Mentions } & \multirow{4}{*}{0} & Count & 59 & 197 & 49 & 305 \\
\hline & & $\%$ of mentions & 19.3 & 64.6 & 16.1 & 100 \\
\hline & & $\%$ of brand & 81.9 & 100 & 86 & 93.6 \\
\hline & & $\%$ of total & 18.1 & 60 & 15 & 93.6 \\
\hline & \multirow{4}{*}{1} & Count & 13 & 0 & 7 & 20 \\
\hline & & $\%$ of mentions & 65 & 0 & 35 & 100 \\
\hline & & $\%$ of brand & 18.1 & 0 & 12.3 & 6.1 \\
\hline & & $\%$ of total & 4 & 0 & 2.1 & 6.1 \\
\hline & \multirow{4}{*}{2} & Count & 0 & 0 & 1 & 1 \\
\hline & & $\%$ of mentions & 0 & 0 & 100 & 100 \\
\hline & & $\%$ of brand & 0 & 0 & 1.8 & .3 \\
\hline & & $\%$ of total & 0 & 0 & .3 & .3 \\
\hline & \multirow{4}{*}{ Total } & Count & 72 & 197 & 57 & 326 \\
\hline & & $\%$ of mentions & 22.1 & 60.4 & 17.5 & 100 \\
\hline & & $\%$ of brand & 100 & 100 & 100 & 100 \\
\hline & & $\%$ of total & 22.1 & 60.4 & 17.5 & 100 \\
\hline \multirow{24}{*}{ Hashtags } & \multirow{4}{*}{0} & Count & 15 & 114 & 19 & 148 \\
\hline & & $\%$ of hashtag & 10.1 & 77 & 12.8 & 100 \\
\hline & & $\%$ of brand & 20.8 & 57.9 & 33.3 & 45.4 \\
\hline & & $\%$ of total & 4.6 & 35 & 5.8 & 45.4 \\
\hline & \multirow{4}{*}{1} & Count & 41 & 28 & 23 & 92 \\
\hline & & $\%$ of hashtag & 44.6 & 30.4 & 25 & 100 \\
\hline & & $\%$ of brand & 56.9 & 14.2 & 40.4 & 28.2 \\
\hline & & $\%$ of total & 12.6 & 8.6 & 7.1 & 28.2 \\
\hline & \multirow{4}{*}{2} & Count & 7 & 44 & 15 & 66 \\
\hline & & $\%$ of hashtag & 10.6 & 66.7 & 22.7 & 100 \\
\hline & & $\%$ of brand & 9.7 & 22.3 & 26.3 & 20.2 \\
\hline & & $\%$ of total & 2.1 & 13.5 & 4.6 & 20.2 \\
\hline & \multirow{4}{*}{3} & Count & 7 & 11 & 0 & 18 \\
\hline & & $\%$ of hashtag & 38.9 & 61.1 & 0 & 100 \\
\hline & & $\%$ of brand & 9.7 & 5.6 & 0 & 5.5 \\
\hline & & $\%$ of total & 2.1 & 3.4 & 0 & 5.5 \\
\hline & \multirow{4}{*}{4} & Count & 2 & 0 & 0 & 2 \\
\hline & & $\%$ of hashtag & 100 & 0 & 0 & 100 \\
\hline & & $\%$ of brand & 2.8 & 0 & 0 & .6 \\
\hline & & $\%$ of total & .6 & 0 & 0 & .6 \\
\hline & \multirow{4}{*}{ Total } & Count & 72 & 197 & 57 & 326 \\
\hline & & $\%$ of hashtag & 22.1 & 60.4 & 17.5 & 100 \\
\hline & & $\%$ of brand & 100 & 100 & 100 & 100 \\
\hline & & $\%$ of total & 22.1 & 60.4 & 17.5 & 100 \\
\hline
\end{tabular}

\section{Dialogical Loop Maintenance}

It can be said that it is common for followers to interact with the brand, which include comments on almost all publications, in fact, these can be observe in $100 \%$ of the posts of Ralph Lauren, in $97.5 \%$ of the texts of Zara and in $97.2 \%$ of the publications of H\&M (no statistically significant differences between companies). However, the number of interactions per post does show dissimilarities depending on the brand $\left(x^{2}=249.602 ; p\right.$ $=0.001)$, with an effect size large $(\mathrm{V}-\mathrm{Cramer}=0.619, \mathrm{p}=0.001)$. Thus, the followers 
of H\&M perform an average of 14.07 interactions per publication (with a minimum of 0 and a maximum of 77), data that amounts to 35.25 in the case of Zara (minimum $=0$ and maximum $=180$ ) and to 103.40 in the case of Ralph Lauren. This last company stands out for being the only one that does not have any post without comment, since its minimum is 3 , in addition, it has managed to obtain a maximum of 1395 comments in a publication that contains a video in which you can observe a group of dogs wearing clothes from Ralph Lauren's pet collection.

When considering whether the brand responds to comments made by its followers again there are differences between companies $\left(x^{2}=70.867, p=0.000\right)$, although in this case the effect size is medium $(\mathrm{V}-\mathrm{Cramer}=0.466, \mathrm{p}=0.000)$. A) Yes, highlights the Ralph Lauren case, as it does not interact with its followers in any occasion, however, H\&M do so in $23.6 \%$ of posts and Zara in $57.4 \%$.

In addition, the average of comments per publication that each brand also makes shows dissimilarities $\left(\mathrm{x}^{2}=79.049 ; \mathrm{p}=0.000\right)$ and has an average effect size $(\mathrm{V}-\mathrm{Cramer}$ $=0.348 ; \mathrm{p}=0.000)$. In this way, Zara makes an average of 1.86 comments per publication (with a minimum of 0 and a maximum of 15), figure that is reduced to 0.40 in the case of H\&M (minimum 0 and maximum of 5) and to 0 in that of Ralph Lauren.

With reference to the reactions, it should be noted that only statistically significant differences between brands in the case of "makes me angry " $\left(x^{2}=200.344 ; p=0.000\right)$, although the size of the effect found is large (V-Cramer $=0.554 ; p=0.000)$. In particular, the followers of Zara are those who resort to this negative rating on more occasions $(\mathrm{M}=2.87)$, followed by Ralph Lauren $(\mathrm{M}=1.95)$ and $\mathrm{H} \& \mathrm{M}(\mathrm{M}=0.53)$ (see table 3$)$. In this sense, and in spite of not existing significant differences between brands, the publication that has generated the most reactions between users belongs to Ralph Lauren. It is a post with seven photographs showing an elegant home with Ralph Lauren Home products and that has managed to obtain a total of 31244 reactions, being only three of them negative (two "it makes me sad" and one "makes me angry").

Table 3. Reactions of users to publications

\begin{tabular}{|c|l|l|l|l|l|l|}
\hline \multirow{2}{*}{ Brand } & \multicolumn{1}{|c|}{ Kind of reaction } & \multicolumn{1}{|c|}{$\mathbf{N}$} & \multicolumn{1}{|c|}{ Min. } & Max. & Average & \multicolumn{1}{c|}{$\begin{array}{c}\text { Standard } \\
\text { deviation }\end{array}$} \\
\hline \multirow{5}{*}{ H\&M } & Total number of reactions & 72 & 177 & 5340 & 1815.60 & 1164.976 \\
\cline { 2 - 7 } & Number of "I like it" & 72 & 174 & 5063 & 1729.94 & 1116.563 \\
\cline { 2 - 7 } & Number of "I love it" & 72 & 3 & 243 & 75.33 & 50.376 \\
\cline { 2 - 7 } & Number of "Laughs" & 72 & 0 & 6 & .93 & 1.260 \\
\cline { 2 - 7 } & Number of "I'm scared" & 72 & 0 & 31 & 7.06 & 6.026 \\
\cline { 2 - 7 } & Number of "I'm sad" & 72 & 0 & 2 & .15 & .433 \\
\cline { 2 - 7 } & Number of "I'm angry" & 72 & 0 & 3 & .53 & .750 \\
\cline { 2 - 7 } & Number of "LGBT proud" & 72 & 0 & 15 & .75 & 2.949 \\
\cline { 2 - 7 } & Number of "I'm proud" & 72 & 0 & 34 & .89 & 5.023 \\
\hline \multirow{5}{*}{ Zara } & Total number of reactions & 197 & 56 & 7486 & 2550.03 & 1480.285 \\
\cline { 2 - 7 } & Number of "I like it" & 197 & 55 & 6975 & 2423.11 & 1399.226 \\
\cline { 2 - 7 } & Number of "I love it" & 197 & 0 & 495 & 112.45 & 81.296 \\
\cline { 2 - 7 } & Number of "Laughs" & 197 & 0 & 46 & 2.80 & 5.167 \\
\cline { 2 - 7 } & Number of "I'm scared" & 197 & 0 & 46 & 7.35 & 6.546 \\
\cline { 2 - 7 } & Number of "I'm sad" & 197 & 0 & 5 & .28 & .606 \\
\cline { 2 - 7 } & Number of "I'm angry" & 197 & 0 & 41 & 2.87 & 4.462 \\
\cline { 2 - 7 } & Number of "LGBT proud" & 197 & 0 & 131 & .76 & 9.335 \\
\hline
\end{tabular}


Paper-The Dialogical Potential of Facebook: The Case of Fashion Brands

\begin{tabular}{|l|l|l|l|l|l|l|}
\hline & Number of "I'm proud" & 197 & 0 & 21 & .42 & 2.286 \\
\hline \multirow{4}{*}{$\begin{array}{l}\text { Ralph Lau- } \\
\text { ren }\end{array}$} & Total number of reactions & 57 & 289 & 31244 & 2245.63 & 4192.454 \\
\cline { 2 - 7 } & Number of "I like it" & 57 & 268 & 27950 & 1999.89 & 3713.798 \\
\cline { 2 - 7 } & Number of "I love it" & 57 & 0 & 2996 & 217.11 & 450.348 \\
\cline { 2 - 7 } & Number of "Laughs" & 57 & 0 & 299 & 7.88 & 40.012 \\
\cline { 2 - 7 } & Number of "I'm scared" & 57 & 0 & 286 & 16.12 & 38.682 \\
\cline { 2 - 7 } & Number of "I'm sad" & 57 & 0 & 10 & .44 & 1.402 \\
\cline { 2 - 7 } & Number of "I'm angry" & 57 & 0 & 37 & 1.95 & 6.166 \\
\cline { 2 - 7 } & Number of "LGBT proud" & 57 & 0 & 2 & .09 & .391 \\
\cline { 2 - 7 } & Number of "I'm proud" & 57 & 0 & 0 & .00 & .000 \\
\hline
\end{tabular}

However, differences between brands can be observed when considering the number of times, the publication has been shared by users $\left(x^{2}=292.529, \mathrm{p}=0.004\right)$, with a large effect size $(\mathrm{V}-\mathrm{Cramer}=0,670 ; \mathrm{p}=0.004)$. Thus, the publications of Zara are shared an average of 49.43 times (with a minimum of 0 and a maximum of 432 ), those of H\&M have an average of 54.67 (minimum $=0$ and maximum $=356$ ), a figure that increases considerably when observing the case of Ralph Lauren, since it has an average of 186.86 (minimum $=0$ and $\operatorname{maximum}=2203$ ).

\section{Conclusion}

The main results of the present study show that the examined fashion brands comply only partially with the principles dialogical analyzed. In addition, it should be noted that there is no consensus among the profiles studied with reference to the degree of compliance with these principles, since, as has been able to observe, it is usual to find statistically significant differences in brand function.

In general, it could be considered that the companies analyzed should contribute with more useful information for their audiences, since, although they often include images, it is not usual to insert videos. However, brands use different strategies in relation to this topic. Zara, for instance, is the brand that has more publications with photographs and Ralph Lauren the least, but this distribution is reversed in the case of videos. These two companies show important differences when considering the links, since Zara introduces them in almost all its posts while Ralph Lauren does it only in a residual way. In case of Zara is especially striking, as it is the only brand that includes more than one link and that has a link that does not redirect to a web.

When considering the conservation of visitors, it should be noted that there is a situation similar to the previous one, since this principle is only fulfilled partially and Zara and Ralph Lauren show important dissimilarities. In general, it can be said that the frequency of publication is very low for all profiles, although Zara is the one that publishes the most and Ralph Lauren the least. But nevertheless, brands do incorporate corporate links, as it has not been possible to find one external.

The interest of the brands examined for generating repeated visits is not perfect. For example, it is not usual for the companies analyzed to include mentions. Especially striking is the case of Zara, as it does not introduce any, while Ralph Lauren is the only brand that inserts more than one mention in its publications. Although the use of 
hashtags is more common, they are going to produce differences between the profiles studied, since Zara is the one that uses them the least and H\&M the most.

Before this, it could be said that the companies examined do not maintain the dialogical loop with its followers. Thus, although it is usual for users to interact with brands through reactions and comments, it is not often that institutions respond. Thus, it should be noted that Ralph Lauren does not answer in any occasion, despite the fact that its publications are the most commented.

Therefore, and in spite of the differences found among the companies examined, we can conclude that, although Facebook has a wide dialogical potential, the fashionable brands use it minimally. Previous works have already shown that the sector of Fashion does not usually dialogue with its followers in social networks, specifically through Twitter [23].

Thus, despite the fact that academy has frequently studied the dialogical principles as a series of tools capable of building relationships between a institution and its public [39], the research carried out shows that organizations normally do not maintain relationships with their audience based on interactivity and commitment [38]. Therefore, it could be said that it is not usual for the profession to fully use the potential that the Internet and websites offer to build relationships with their audiences [19].

In effect, organizations do not usually take full advantage of the potential dialog that offers on-line communication to interact with its stakeholders, either through websites [9];[15]; [32];[25] or social networks such as Twitter [28] and Facebook [11];[37];[5]. In fact, and when examining the particular case of this last social network, it can be considered that the principle of dialogical loop is the least used by institutions [11]. This situation may be due to organizations not wanting to invest more time and resources in bidirectional communication, or maybe this situation occurs because they are not willing to lose control of their communication [38].

Finally, it should be noted that, although we consider appropriate to have analyzed only the Facebook social network given its importance, this situation could be considered as the main limitation of the present study, since companies examined may or may not be taking advantage of the dialogical potential in a different way that offer other social media especially interesting for the audiences of the fashion brands, such as Instagram (social network based on photography) or YouTube (platform focused on videos). Thus, a future line of research that consists in analyzing and comparing the dialogue maintained by the fashion brands with its audiences through digital platforms that pay special attention to the photographs and videos is now open.

\section{$7 \quad$ References}

[1] Baird, C.H. and Parasnis, G. (2011), "From social media to social customer relationship management", Strategy \& Leadership, Vol. 39 No. 5, pp. 30-37. https://doi.org/10.1108/ $\underline{10878571111161507}$

[2] Baumgarten, C. (2011), "Chirping for charity: How U.S. nonprofit organizations are using Twitter to foster dialogic communication", The Elon Journal of Undergraduate Research in Communications, Vol. 2 No 2, pp. 5-14. 
[3] Berelson, B. (1952), Content Analysis in Communication Research, The Free Press, Glencoe - Illinois.

[4] Berthon, P.R., Pitt, L.F., Plangger, K. and Shapiro, D. (2012), "Marketing meets web 2.0, social media, and creative consumers: Implications for international marketing strategy", Business Horizons, Vol. 55 No. 3, pp. 261-271. https://doi.org/10.1016/j.bushor.2012.01. $\underline{007}$

[5] Coelho, P., Correia, P., \& Garcia Medina, I., (2017). Social Media: A New Way of Public and Political Communication in Digital Media. International Journal of Interactive Mobile Technologies (iJIM). ISSN: 1865-7923. Vol 11, No 6, 150-157. https://doi.org/10.3991/ ijim.v11i6.6876

[6] Correia, P. \& Garcia Medina, I., (2014). Digital Social Media: An Interactive Technology Incorporated as a Competitive Advantage for Business. International Journal of Interactive Mobile Technologies (iJIM). ISSN: 1865-7923. V. 8, (2), 31-35; https://doi.org/10.3991/ ijim.v8i2.3576

[7] Correia, P. \& Garcia Medina, I., (2012). The Importance of Social Media for Commerce. A Case Study in Madeira (Portugal). International Journal of Interactive Mobile Technologies (iJIM). ISSN: 2177-6288. V. 6, (1), 208-222; https://doi.org/10.3991/ijim.v6i1.1825

[8] Deng, Z., Lu, Y., Wei, K.K. and Zhang, J. (2010), "Understanding customer satisfaction and loyalty: An empirical study of mobile instant messages in China”, International Journal of Information Management, Vol. 30 No. 4, pp. 289-300. https://doi.org/10.1016/j.ijinfomgt.2009.10.001

[9] Durántez-Stolle, P. (2017), "Interacción y participación en salas de prensa virtuales de las empresas del IBEX 35”, El Profesional de la Información, Vol. 26 No. 2, pp. 228-237. https://doi.org/10.3145/epi.2017.mar.09

[10] Grančay, M. (2014), “Airline facebook pages - a content analysis”, European Transport Research Review, Vol. 6 No. 3, pp. 213-223. https://doi.org/10.1007/s12544-013-0126-9

[11] Haro-de-Rosario, A., Sáez-Martín, A. and Gálvez-Rodríguez, M.M. (2017), "Facebook as a dialogic strategic tool for european local governments", Transylvanian Review of Administrative Sciences, No. 50, pp. 73-89. https://doi.org/10.24193/tras.2017.0005

[12] Hoffman, E., Khanfar, N.M., Harrington, C. and Kizer, L.E. (2016), "The lasting effects of social media trends on advertising", Journal of Business \& Economics Research, Vol. 14 No. 3, pp. 75-82. https://doi.org/10.19030/jber.v14i3.9747

[13] Hvass, K.K. (2014), "Post-retail responsibility of garments - a fashion industry perspective", Journal of Fashion Marketing and Management, Vol. 18 No. 4, pp. 413-430. https://doi.org/10.1108/jfmm-01-2013-0005

[14] Interbrand (2016), "Best global brands 2016. Rankings", available at: http://interbrand.com/best-brands/best-global-brands/2016/ranking/\#?listFormat=sq (accessed 19 January 2018). https://doi.org/10.1108/978-1-78743-781-420181007

[15] Kent, M.L., Taylor, M. and White, W.J. (2003), "The relationship between web site design and organizational responsiveness to stakeholders", Public Relations Review, Vol. 29 No. 1, pp. 63-77. https://doi.org/10.1016/s0363-8111(02)00194-7

[16] Kent, M.L. and Taylor, M. (1998), "Building dialogic relationships through the World Wide Web”, Public Relations Review, Vol. 24 No. 3, pp. 321-334. https://doi.org/10.1016/ $\underline{\mathrm{s} 0363-8111(99) 80143-\mathrm{x}}$

[17] Kim, A.J. and Ko, E. (2012), "Do social media marketing activities enhance customer equity? An empirical study of luxury fashion brand", Journal of Business Research, Vol. 65 No. 10, pp. 1480-1486. https://doi.org/10.1016/j.jbusres.2011.10.014

[18] Krippendorff, k. (2004), Content Analysis: An Introduction to Its Methodology, Sage Publications, California. 
[19] Levenshus, A. (2010), "Online relationship management in a presidential campaign: A case stuy of the Obama campaign's management of its internet-integrated grassroots effort", Journal of Public Relations Research, Vol. 22 No. 3, pp. 313-335. https://doi.org/10.1080/1 $\underline{0627261003614419}$

[20] Maestro, L., García, J.V. and Pérez, M.J. (2016), “The general-interest digital press as advertising platform: Changes in its business model", Revista Latina de Comunicación Social, No. 71, pp. 1048-1068.

[21] McCorkindale, T. (2010), "Can you see the writing on my wall? A content analysis of the Fortune 50's Facebook social networking sites”, Public Relations Journal, Vol. 4 No. 3, available at: http://citeseerx.ist.psu.edu/viewdoc/download?doi=10.1.1.470.6602\&rep= rep1\&type $=$ pdf (accessed 19 January 2018).

[22] Mohr, I. (2013), "The impact of social media on the fashion industry", Journal of Applied Business and Economics, Vol. 15 No. 2, pp. 17-22.

[23] Navarro-Beltrá, M., Miquel-Segarra, S. and García Medina, Irene (2016), "El uso del potencial dialógico de Twitter: el caso de las marcas de moda", Ámbitos: Revista Internacional de Comunicación, 36, available at: http://institucional.us.es/ambitos/?p=2836 (accessed 19 January 2018). https://doi.org/10.12795/ambitos.2017.i36.02

[24] Oulasvirta, A., Rattenbury, T., Ma, L. and Raita, E. (2012), "Habits make smartphone use more pervasive", Personal and Ubiquitous Computing, Vol. 16 No. 1, pp. 105-114. https:// doi.org/10.1007/s00779-011-0412-2

[25] Park, H. and Reber, B. (2008), "Relationship building and the use of websites: How Fortune 500 companies use their websites to build relationships", Public Relations Review, Vol.34 No 4, pp. 409-411. https://doi.org/10.1016/j.pubrev.2008.06.006

[26] Pedersen, E.R., Naranjo, D. and Marshall, G.N. (2017), "Recruitment and retention of young adult veteran drinkers using Facebook", Plos One, Vol. 12 No. 3, available at: http://journals.plos.org/plosone/article?id=10.1371/journal.pone.0172972 (accessed 19 January 2018). https://doi.org/10.1371/journal.pone.0172972

[27] Quiles-Soler, M.C., Martínez-Sala, A.M. and Monserrat-Gauchi, J. (2016), "Gestión de la comunicación on-line en la empresa de franquicia. El uso de Facebook en el sector 'servicios"”, Sphera Publica, Vol. 1 No. 16, pp. 61-76. https://doi.org/10.6035/21740992.2012. $\underline{3.7}$

[28] Rybalko, S. and Seltzer, T. (2010), "Dialogic communication in 140 characters or less: How Fortune 500 companies engage stakeholders using Twitter", Public Relations Review, Vol. 36 No. 4, pp. 336-341. https://doi.org/10.1016/j.pubrev.2010.08.004

[29] Sharma, R.B. and Sahni, M.M. (2015), "Evaluating the efficacy of Facebook communities \& Twitter tweets on brand equity: An empirical study of Fashion Brands", Advances in Economics and Business Management (AEBM), Vol. 2 No. 5, pp. 503-508.

[30] Shen, B. and Bissell, K. (2013), "Social media, social me: A content analysis of companies' use of Facebook", Journal of Promotion Management, Vol. 19 No. 5, pp. 629-651. https://doi.org/10.1080/10496491.2013.829160

[31] Straker, K. and Wrigley, C. (2016), "Emotionally engaging customers in the digital age: The case study of "Burberry love"', Journal of Fashion Marketing and Management, Vol. 20 No. 3, pp. 276-299. https://doi.org/10.1108/jfmm-10-2015-0077

[32] Taylor, M., Kent, M.L. and White, W.J. (2001), "How activist organizations are using the internet to build relationships", Public Relations Review, Vol .27 No 3, pp. 263-284. https://doi.org/10.1016/s0363-8111(01)00086-8

[33] Touchette, B., Schanski, M. and Lee, S.E. (2015), “Apparel brands' use of Facebook: An exploratory content analysis of branded entertainment”, Journal of Fashion Marketing and 
Management, Vol. 19 No. 2, pp. 107-119. https://doi.org/10.31274/itaa proceedings$180814-667$

[34] Tyrawski, J. and De Andrea, D.C. (2018), "Pharmaceutical companies and their drugs on social media: A content analysis of drug information on popular social media sites", Journal of Medical Internet Research, Vol. 17 No. 6, available at: Disponible en: https://www. jmir.org/2015/6/e130/ (accessed 19 January 2018). https://doi.org/10.2196/jmir.4357

[35] Verhoeven, P., Tench, R., Zerfass, A., Moreno, A. and Vercic, Dejan (2012), "How European PR practitioners handle digital and social media", Public Relations Review, Vol. 38 No. 1, pp. 162-164. https://doi.org/10.1016/j.pubrev.2011.08.015

[36] Wallace, L., Willson, J. and Miloch, K. (2011), "Sporting Facebook: A content analysis of NCAA organizational sport pages and big 12 conference athletic department pages", International Journal of Sport Communication, Vol. 4 No. 4, pp. 422-444. https://doi.org/10. $\underline{1123 / \text { ijsc.4.4.422 }}$

[37] Waters, R.D., Canfield, R, R., Foster, J.M. and Hardy, E.E. (2011), “Applying the dialogic theory to social networking sites. Examining how university health centers convey health messages on Facebook", Journal of Social Marketing, Vol. 1 No. 3, pp. 211-227. https:// doi.org/10.1108/20426761111170713

[38] Waters, R.D. and Williams, J.M. (2011), "Squawking, tweeting, cooing, and hooting: Analyzing the communication patterns of government agencies on Twitter", Journal of Public Affairs, Vol. 11 No. 4, pp. 353-363. https://doi.org/10.1002/pa.385

[39] Watkins, B.A. (2017), "Experimenting with dialogue on Twitter: An examination of the influence of the dialogic principles on engagement, interaction, and attitude", Public Relations Review, Vol. 43 No. 1, pp. 163-171. https://doi.org/10.1016/j.pubrev.2016.07.002

[40] Wimmer, R.D. and Dominick, J.R. (2001), Introducción a la Investigación de Medios Masivos de Comunicación, International Thomson Editores, México.

\section{Authors}

Marián Navarro-Beltrá is a Lecturer and Researcher at the Department of Communication Sciences of the Catholic University of Murcia (UCAM). Graduated in Advertising and Public Relations by the University of Alicante and $\mathrm{PhD}$. by the same institution.

Irene Garcia Medina is a Lecturer in Marketing, Business Management Department, Glasgow Caledonian University. Irene.Garcia2@gcu.ac.uk

Pedro A. P. Correia is a Lecturer at the University of Madeira, Funchal, Portugal and $\mathrm{PhD}$ in Interactive Digital Communication and Marketing. pacorreia@staff.uma.pt

Article submitted 2019-05-19. Resubmitted 2019-10-07. Final acceptance 2019-10-08. Final version published as submitted by the authors. 